\title{
BMJ Open Promoting leadership and quality improvement through external inspections of management of sepsis in Norwegian hospitals: a focus group study
}

\author{
Gunnar Husabø (D) , ${ }^{1,2}$ Inger Lise Teig, ${ }^{2}$ Jan C Frich, ${ }^{3}$ Gunnar Tschudi Bondevik, ${ }^{2,4}$ \\ Einar Hovlid (1) ${ }^{1,2}$
}

To cite: Husabø G, Teig IL, Frich JC, et al. Promoting leadership and quality improvement through external inspections of management of sepsis in Norwegian hospitals: a focus group study. BMJ Open 2020;10:e041997. doi:10.1136/ bmjopen-2020-041997

- Prepublication history and additional material for this paper is available online. To view these files, please visit the journal online (http://dx.doi.org/10. 1136/bmjopen-2020-041997).

Received 22 June 2020 Revised 20 0ctober 2020 Accepted 28 0ctober 2020

Check for updates

(c) Author(s) (or their employer(s)) 2020. Re-use permitted under CC BY-NC. No commercial re-use. See rights and permissions. Published by BMJ.

${ }^{1}$ Department of Social Science, Høgskulen på Vestlandet,

Sogndal, Norway

${ }^{2}$ Department of Global Public Health and Primary Care, Universitetet i Bergen, Bergen, Norway

${ }^{3}$ Institute of Health and Society, Universitetet i 0slo, Oslo,

Norway

${ }^{4}$ National Centre for Emergency Primary Health Care, NORCE

Norwegian Research Centre AS, Bergen, Norway

Correspondence to

Gunnar Husabø:

gunnar.husabo@hvl.no

\section{ABSTRACT}

Objective Inspections and other forms of external assessment may contribute to positive changes in the health services, but the mechanisms of such change remain unclear. We did a study to explore how external inspections may foster clinical improvement in hospitals. Design Focus group study.

Setting Statutory inspections of sepsis treatment in hospital emergency departments in Norway.

Participants Clinicians, managers and inspection teams involved with the inspections of sepsis treatment in emergency departments at four different hospitals. Twelve focus group interviews were carried out, with a total of 47 participants.

Results Three themes emerged as central for understanding how the inspections could contribute to clinical improvement in the emergency departments: (1) increasing awareness about the need to improve the quality of care by providing data on clinical performance, (2) building acceptance for improvement through professional credibility and focus on clinical practice, and (3) fostering leadership commitment.

Conclusion Our findings suggest that the inspections have the potential to enhance hospital management and staff's understanding of complicated care processes and help strengthen the organisational commitment to bring about systemic quality improvements.

\section{INTRODUCTION}

External inspection, also referred to as statutory supervision, is an external assessment strategy that is used to evaluate if healthcare providers meet accepted quality standards. Compared with other forms of external assessment, such as certification and accreditation, external inspections differ in that they are run by government bodies and subject to country-specific regulations. ${ }^{1}$ While the subject and scope vary greatly from one inspection to another, most inspections have in common the goal of improving the quality

\section{Strength and limitations of this study}

- Focus group interviews in hospitals that had achieved improvement in key clinical procedures following an inspection provided information-rich cases of how inspections can contribute to quality improvement.

- The interviews elicited new insights into how inspections can enhance understanding of the clinical system and promote leadership in quality improvement efforts.

- We did not explore change mechanisms related to anticipatory effects resulting from the announcement of upcoming inspections.

- The generalisability of our findings and interpretations are dependent on the organisational and procedural context in which inspections are being held.

of care provided by the organisations subject to the inspection. ${ }^{2}$

The rationale for why external assessment strategies could lead to improved quality is that managers will review the results of assessments and implement changes that are necessary for better and safer healthcare. ${ }^{1}$ Such effects might function through directive steps, in which the inspectors guide or force the health organisation to act in a specific way. They can also be a result of 'softer' mechanisms, such as if inspections lead to a shift in focus and organisational objectives at the service provider. $^{3}$ In either case, the inspectors themselves cannot directly affect the quality of care being provided. As such, they must find ways to improve the quality of care through influencing the care processes and internal controls at the hospitals. External inspection can thus be seen as a way of boosting the internal quality and patient safety improvement work. ${ }^{4}$ 
Following the argument above, the effectiveness of inspections would likely depend on the degree to which they support organisational attributes and work processes associated with successful improvement. The literature describes readiness for change as a main dimension influencing the chance of success when implementing improvement efforts in healthcare organisations. ${ }^{5}$ This view is rooted in a notion of organisations as communities that contribute to the amplification and development of knowledge rather than merely entities of hierarchical information processing. ${ }^{6}$

Research has shown mixed effects of inspections on improvement in healthcare organisations. Some studies have found care practices to improve following inspections but not been able to fully establish the association between the inspections and the improvements. ${ }^{78}$ Other studies have not found any improvements following inspections at all. ${ }^{9}{ }^{10}$ Gaining a deeper insight into the mechanisms of change in connection with external inspections is needed in order to understand how and under what circumstances inspections might lead to substantial, long-lasting improvement. ${ }^{11} 12$

Our overall aim was to study how external inspections may foster clinical improvement, using the case of a nationwide inspection of sepsis treatment in emergency departments at Norwegian hospitals. We sought to explore clinicians', managers' and inspection teams' experiences of being involved in the inspection process and to explore their views on how inspections can affect the quality of care.

\section{METHODS}

\section{Study design}

The study is a part of an ongoing research on the impact of external inspection of sepsis diagnosis and treatment in emergency departments in Norwegian hospitals. The study protocol has been described previously. ${ }^{13}$ The inspections were planned and directed by the Norwegian Board of Health Supervision (NBHS) at 24 hospitals with acute care functions.

For this study, we chose a qualitative approach, conducting focus group interviews with clinicians, managers and inspectors. We found this to be a wellsuited method of inquiry, as the focus group discussion can provide interpretive insights into the participants experiences and opinions. ${ }^{14}$ Our approach is informed by a realist paradigm, its concept of causal mechanisms providing a framework for understanding the conditions under which inspections may foster clinical improvement. ${ }^{15}$ The study follows Standards for Reporting Qualitative Research (SRQR) guidelines. ${ }^{16}$

\section{The sepsis inspections}

In Norway, health services are publicly funded and based on the principle of universal and equitable access. They are mandated by legislation to be safe, effective and provided in accordance with sound professional standards. NBHS is responsible for ensuring that health services meet these requirements. One of their main supervision approaches is nationwide thematic inspections of services, prioritised on the basis of information about risk and vulnerability. During these inspections, NBHS or the County Governors, who are local representatives of the central government, investigate services and report any identified non-conformities. While NBHS can impose its authority on healthcare organisations and individual healthcare workers through a wide range of responses and sanctions, the reactions issued after nationwide inspections are normally limited to instructing the organisations to correct the situation. The inspectors will then follow-up the organisation until the non-conformity is considered satisfactorily corrected. ${ }^{17}$

NBHS chose diagnosis and treatment of sepsis in hospital emergency departments as a subject of a thematic inspection starting in 2016 because patients presenting to emergency departments with sepsis often receive substandard care. ${ }^{18}$ Delayed treatment is a major challenge, as time is of paramount importance in treatment of sepsis. ${ }^{19}{ }^{20}$ Because early treatment depends on early diagnosis and recognition, ${ }^{21}{ }^{22}$ the failures in expediting the treatment often come down to failures in recognising the diagnosis at an early stage. ${ }^{18}$

There were six regional inspection teams. Each team included three to four inspectors from the County Governors with prior training and experience from either healthcare or law. Additionally, each team had an external medical specialist who had extensive clinical experience from working with sepsis diagnosis and treatment.

Methodologically, the inspections were system audits. ${ }^{23}$ NBHS used existing guidelines and conferred with experts to formulate a set of quantitative criteria for recommended diagnosis and treatment of sepsis. ${ }^{24}{ }^{25}$ At inspection, which typically lasted for 2 days, the team gathered data from the electronic health records of a set of 66 patients with sepsis and evaluated the care given against the criteria. As is customarily done in system audits, the inspection teams also reviewed documentation of relevant procedures and interviewed clinicians and managers responsible for the care of patients with sepsis. At the final day of inspection, the main findings were presented to the hospital management and staff in a closing meeting. Afterwards, the inspection team wrote up a report that included findings and a list of non-conformities. The report was sent as a draft to the hospital's executive management for comments and eventually finalised and released to the public via the internet. A translated version of the report from one of the inspections is provided as online supplemental file 1 , and an overview of the findings from the four inspections included in this study is provided as online supplemental file 2.

\section{Participants and data collection}

This study draws on data from 12 focus group interviews with clinicians, managers and inspection teams involved in the inspection of four of the hospitals (designated A, B, 
$\mathrm{C}$ and $\mathrm{D})$. The interviews were conducted after the initial inspection, in the period from March 2017 to November 2018. Analyses that included all inspected hospitals found that, on average, the inspection had a positive effect on several care process measures. ${ }^{26}$ We chose to include these four hospitals in the present study because they were among the hospitals that showed substantial improvements following the inspection. An overview of the improvements in a key indicator, time to antibiotic treatment, is provided in online supplemental file 2.

We conducted separate focus group interviews with clinicians, managers and the inspection teams at each hospital. The focus groups were sized from three to five participants and included in total 47 interviewees: 15 clinicians, 16 managers and 16 inspection team members.

The groups of clinicians consisted of physicians and nurses who had diagnosis and treatment of patients with sepsis in the emergency department as a part of their daily tasks. The managers were either head nurses at emergency departments, chief physicians or heads of clinics. As such, the manager focus groups had a mix of interviewees in managerial roles and interviewees with combined responsibility for management and patient care. Clinicians and managers were recruited to the focus groups via contact persons with responsibility for quality management in the hospitals. We recruited all members currently on the inspection team who were available to attend the interview. As the members of the inspection teams changed over time, some inspection team interviewees had not participated in the inspections at the specific hospitals included in our study. The participants were informed beforehand about the purpose of the interviews and they signed a form agreeing to participate in the study. No compensation was given for participation in the study.

The interviews were conducted by GH (male, MSc), except for two interviews that were conducted in collaboration with $\mathrm{EH}$ (male, $\mathrm{MD} / \mathrm{PhD}$ ). GH had no previous affiliation with NBHS but had experience from performance audit work in healthcare organisations. EH had a part-time position as a researcher in NBHS and had previously participated in NBHS inspections. He was acquainted with some of the interviewees from his work in NBHS.

For hospitals A, B and C, the interviews with clinicians and managers were conducted at the respective hospitals. The interviews with the inspection teams were conducted at County Governors' offices. For hospital D, all interviews were conducted by conference call due to vast travel distances and logistical challenges with convening the inspection team to a physical meeting. The interviewers and the participants were the only ones attending the interviews.

We used three different interview guides, one for each of the three types of groups. The interview guides focused on the impact of the inspections on the quality of care, and the interviews were centred on the experiences from the sepsis inspections (see table 1). Additionally, time was

\begin{tabular}{|c|c|}
\hline Topic & Probes (sample items) \\
\hline \multicolumn{2}{|l|}{$\begin{array}{l}\text { General experience of } \\
\text { the inspection process }\end{array}$} \\
\hline Relevance & $\begin{array}{l}\text { What was the focus of the } \\
\text { inspection? } \\
\text { Are the themes covered in the } \\
\text { inspection relevant for clinical } \\
\text { practice? }\end{array}$ \\
\hline $\begin{array}{l}\text { Dialogue between } \\
\text { inspection team and } \\
\text { hospital }\end{array}$ & $\begin{array}{l}\text { How were findings conveyed } \\
\text { to the hospital? How did the } \\
\text { management/staff react to the } \\
\text { findings? }\end{array}$ \\
\hline Process for following up & $\begin{array}{l}\text { What has the hospital done } \\
\text { in response to the identified } \\
\text { non-conformities? } \\
\text { Who were involved in following } \\
\text { up the findings from the } \\
\text { inspection? }\end{array}$ \\
\hline $\begin{array}{l}\text { The role of } \\
\text { management }\end{array}$ & $\begin{array}{l}\text { What are important } \\
\text { management tasks related to } \\
\text { the inspection? }\end{array}$ \\
\hline Contribution to change & $\begin{array}{l}\text { How did the inspection impact } \\
\text { the internal quality improvement } \\
\text { work? } \\
\text { What factors other than the } \\
\text { inspection have had an impact } \\
\text { on quality improvement work? } \\
\text { How is the quality of care now, } \\
\text { compared with before the } \\
\text { inspections? }\end{array}$ \\
\hline
\end{tabular}

devoted to discussing sepsis care in general and specific issues surrounding the organisation of work in emergency departments.

The focus group interviews lasted from 35 to $105 \mathrm{~min}$. After each session, field notes were recorded describing how the interview went and whether there were important contextual factors that should be taken into account in the analysis.

\section{Transcription and analysis}

Interviews were digitally recorded and subsequently transcribed and imported to NVivo Qualitative Data Analysis Software V.12 (QSR International Pty). Participants did not receive copies of transcripts.

We analysed the data using a thematic analytic approach. ${ }^{27}$ After the first interview, before analysing the transcript, EH and GH introduced some preliminary codes (awareness of current and desired practice, leader commitment, use of performance metrics, communication and network, staff engagement and systems thinking). Other codes were added throughout the interviews and the subsequent coding of the material.

Once GH had done the initial coding of the interview transcriptions, $\mathrm{EH}$ and $\mathrm{GH}$ identified potential themes from the data material. We grouped the codes we 
considered relevant for understanding the relationship between inspections and improvement work into these themes. Next, we analysed the interviews, first within each hospital, and then cross-case including all interviews, using the themes as an analytical framework.

As the focus groups were made up of three distinct roles, clinicians, managers and inspection team, we took extra care to compare and contrast the analyses between these roles. The interviews with clinicians and managers were more specific to the inspection in their hospital compared with the interviews with the inspection teams because the inspection teams could draw on experiences from all inspected hospitals in their region.

We read the transcripts and listened to the recorded interviews numerous times to ensure immersion, and we refined, synthesised and reorganised the identified themes according to our developing understanding of the material. We also extracted quotations from the material to illustrate themes and analytical points.

GH translated the quotes into English, and the translations were checked by all co-authors.

\section{Patient and public involvement}

Patient organisations participated in a reference advisory group for the overall research programme that this study is a part of. They were involved from the planning stage on, but they did not directly participate in developing or framing this specific article. We used their inputs to inform the overall study design. Patient organisations strongly advocated the importance of disseminating the study findings to relevant parties. NBHS has held a national, public conference for hospitals, government agencies and patient representatives, where we presented preliminary study findings.

\section{RESULTS}

We identified three themes as central for understanding how the inspections could contribute to clinical improvement in the emergency departments: (1) increasing awareness about the need to improve the quality of care by providing data on clinical performance, (2) building acceptance for improvement through professional credibility and focus on clinical practice and (3) fostering leadership commitment.

\section{Increasing awareness about the need to improve the quality of care by providing data on clinical performance}

According to the clinicians, managers and inspection teams, the discrepancy between guidelines and clinical practice was in part caused by the heterogeneous nature of the group of patients with sepsis and by how sepsis can manifest itself through various symptoms. They explained that deciding the course of the patient care is challenging, that the clinical processes of diagnosing and treating sepsis is complex and that judgements often are being made under quite stressful conditions.
A point that was clearly made during the interviews was that the hospitals lacked systems to monitor the extent to which diagnosis and treatment complied with desired practice and procedures. Though data is entered into patients' electronic health records from the time the patients are admitted to the hospitals, the information is not structured in a way that is easily aggregated so that the hospital can track the performance statistically over time.

One of the members of the inspection team at hospital C, who had long experience from leading system audits, told that this was the first time she had dared to state that an inspection had saved lives. She pointed to the systematic collection and analysis of patient data as the main reason for why the inspection had made a difference:

I think what makes a difference, and impacts very strongly, is simply that we have measured, that we have systematised the findings from the electronic health records, (and) presented this using bar charts. The hospital employees were deeply affected by seeing these data. Across-the-board everyone thought they were very good and (in reality) no one were up to the mark.

Some clinicians found that, while they were not exceedingly surprised by the results, the data presented by the inspection team helped frame the challenges they experienced in their day-to-day activities. Describing how the efforts of improving the patient care had changed after the inspection, a clinician from hospital A referred to how the attention to completing diagnostic procedures quickly increased after the inspection results were presented. It made them 'see through other's eyes' what they already knew:

After the inspection, and after (one of the managers) presented the findings in the auditorium, (the diagnostic work) got a lot more focused. It was nice because in a way... we saw through others eyes what we in reality knew, and then we focused on that work in a whole other way. So these patients have been given much better treatment after the inspection, compared to before.

Having performance data presented by the inspection team can help managers and clinicians re-evaluate their own experiences and assessment of clinical performance. The inspection team of hospital B described how their presentation of data in a closing meeting at one of the hospitals had encouraged the participants at the meeting to share and discuss recent experiences of challenges in the emergency department:

We just displayed our own data, but (the managers and clinicians) brought it up on the agenda. And then someone just pointed out: "We heard that there was a surge of patients yesterday as well". We overheard that a discussion and a dynamic emerged that we could pitch into. 
Building acceptance for improvement through professional credibility and focus on clinical practice

Professional credibility was a topic that was underscored by inspection teams, clinicians and managers. The clinicians and managers expected the inspection teams to include professionals with medical background, and they expected the inspection team to have insight into the requirements and practices of acute functions in hospitals. A manager at hospital A argued that the inclusion of medical experts was important for the legitimacy of the findings from the inspections:

It is crucial that there is someone (on the inspection team) who comes from clinical practice, and possibly also from clinical research, and sort of knows the details of the issues that they enquire into; and who also is going to have an understanding of what the management component of these issues might be. So I think this is crucial for the legitimacy of this inspection.

The inspection teams also shared this view, that the medical experts' knowledge of sepsis care and experience with the day-to-day operations of emergency departments enhanced the legitimacy of the inspections.

Clinicians and managers stressed the need for the inspection teams to have a clear understanding of the work processes in emergency departments. By focusing on how the different processes were interconnected, the inspections identified system-level weaknesses that could produce barriers to timely diagnosis and treatment. One of the managers from hospital D pointed out that one of the strengths of the inspection had been how these findings were related to issues critical to patient care:

The direct effect of the inspection is obvious. In this case one can relate it directly to the patient, even though much is related to systems and how systems are in place to take care of patients presenting with sepsis. But (the inspection) is very efficient, benefiting the patient directly.

A factor that both clinicians and managers pointed out across interviews is that diagnosing and treating sepsis patients involve several different organisational subunits within the hospitals. As such, there are very real organisational hurdles that need to be overcome in order to achieve the desired improvement in clinical performance. The inspection teams' understanding of complicated care processes was especially important because it enabled them to direct the inspection on how different groups of clinicians worked together. This forced the different organisational subunits to take a more birds-eye view of the patient care processes as a whole. A manager from hospital B explained:

I believe that it is positive that someone comes from the outside and then points out that you have to have these things up and running. Because $[\ldots]$ the workday is so hectic that every department is preoccupied with themselves and their work [...] And I think that (the inspection) is a good pry tool, because then we have to cooperate between departments. And you could say that as a hospital we should be able to do this of our own volition, but this has turned out to be difficult.

\section{Fostering leadership commitment}

Because of the challenges of making improvements across different subunits within the hospital, hospital management had an important role in the improvement efforts. In this context, leadership commitment refers to the whole chain of command from the executive director on top to the senior nurses in the emergency department.

Both clinicians, managers and the inspection teams argued that without bringing the clinical managers and leaders on board and making sure that they were invested in this work, it would be exceedingly difficult to achieve successful improvement of the patient care. When discussing experiences with the improvement initiatives that started up after the inspections, a clinician at hospital D commented on the role of managers:

Of course they nag a bit, but often because they want to get better. They are genuinely concerned with the medical issues, and that makes one want to join in.

Similarly, one of the clinicians at hospital C pointed out that it was important that clinical managers were genuinely interested in the improvement efforts:

The clinical managers are actually interested in putting much effort into it, ensuring that one has resources, and that time is allocated to this. And in a way ... they join in and look at the results of what is being presented. [...] And this holds true both for nurses and for doctors; that one gets motivated to continue working (with improvements) and feel a bit acknowledged for the work one does.

An important function of the inspections was how they precipitated communication between different leadership levels on matters related to patient care. A clinician from hospital B described how the inspection report affected the hierarchy from clinic to department, and how this caused ripple effects throughout the organisation:

An inspection makes an impact on the management. The head of clinic just said: "This is not good, this is not good enough. Now; who takes care of what? Now we have to do something different." And the head of department joins in. The heads of departments talk together and in a way you get a whole organization joining ... This is clearly an effect of the inspection; from the top management and downwards. It feels more momentous: Here we need to do something, to close the nonconformities, we need to ... And this has yet more ripple effects. So in that sense, (the inspection) has major consequences, in my opinion. 
Facilitating communication networks that also included the managerial level was reported to be an important part of achieving organisational commitment to the issues of the inspection. The inspection facilitated that a large group of decision makers came together to discuss issues related to patient care.

In the period following the initial report from the inspection, hospitals are expected to develop a response and action plan to the NBHS. Many interviewees explained that this was an occasion for mutual learning between different disciplines and different hierarchies of management. A manager from hospital A argued:

Almost nothing happens one-to-one, right? It happens across supporting professions or laboratory professions and radiology and shift teams and positions. So to get some of this reciprocity in the learning process we have tried bringing together these groups and develop a common response (to the NBHS inspection report).

\section{DISCUSSION}

In this study, we set out to explore how inspections may foster clinical improvements in hospitals. The first theme we identified was related to how the inspections provided data on the quality of care for patients with sepsis. Our findings suggest that by providing these data, the inspection promoted increasing awareness of clinical performance.

Second, we found that there was a need for inspection teams to have a clear understanding of the clinical work and of work processes in the emergency department. Without such knowledge, the legitimacy of the inspection would suffer, and the inspection would be rendered ineffective as a tool for systemic improvements. By directing attention to the interdependencies of the care processes, the inspection could help the hospital to target their efforts on improving the clinical system as a whole.

Lastly, the hospital management seems to be the main conduit through which the inspection team can affect the hospital's work on improving a clinically complex task such as sepsis management. Not only do inspection teams engage managers directly they also play a role in opening up channels of communication between clinical and toplevel management and leadership. External inspections could therefore create arenas for discussion and interprofessional reflection between different levels of management on how the hospital as a whole could improve their services to patients with sepsis.

\section{Strengths and limitations}

The findings and interpretations of this study are intrinsically linked to the organisational and procedural context in which they are being held. Inspections are complex interventions. Reviewing their effects, we need explanatory analyses that bring to bear both theoretical and practical understanding of the intervention and the contexts within which it is being implemented. ${ }^{28}$ The generalisability of the findings should be judged accordingly. We have purposively chosen to study the experiences of actors involved in presumptively successful inspections within a clinically demanding field of patient care. If we had selected less successful cases or studied inspections of another type of theme, for instance administrative tasks, one could expect our findings to diverge substantially. It is also worth noting that the selection of successful inspections was based on disease-specific indicators. Therefore, we do not know whether the inspections had any significant effect on hospital-level performance. ${ }^{29}$

Our focus on change mechanisms related to improvements in quality of care also implies that we have not explored potential costs and adverse side-effects of the inspections. Inspections may impose compliance costs on regulated organisations, including costs related to handling requests for information, consulting the inspection team and acting as guides on site-visits. ${ }^{30}$ If the organisation frequently receives inspections, inquiries or instructions from different regulatory bodies, such costs might add up to a substantial strain, especially on the management and administrative staff. This study should therefore not be considered an exhaustive evaluation of the benefits and disadvantages of the sepsis inspections or inspections in general.

Furthermore, we do not argue that the aspects highlighted in this study are the only mechanisms that might be set in motion during an inspection process. One line of argument worth mentioning in this respect is that the prospect of being inspected in itself can initiate improvement efforts. ${ }^{31}$ Though the search for such anticipatory effects is an important avenue of research, the focus of this study has been on how the findings and recommendations from the inspections, and the interaction with the inspection teams, might influence the hospitals' improvement efforts.

\section{Interpretation in relation to previous studies}

Our analyses echo previous research regarding how inspections with a patient-centred focus might promote awareness among clinicians and managers. ${ }^{32}$ Furthermore, our analyses lend support to studies highlighting how using data in external assessments of quality of care can help hospitals track improvement. ${ }^{33}$ Providing measurable data seems especially pertinent in the case of the sepsis inspections, as previous studies have shown the importance of performance metrics in fostering change in clinical behaviour in care for patients with sepsis. ${ }^{34}$

Some authors have argued that if external assessment schemes lead to increased use of data, they do so primarily through a strengthening of the bureaucratic control in the organisation. ${ }^{35}$ We, however, found that the quality metrics were not considered as being solely within the purview of bureaucratic control; the professionals in the organisation viewed the use of data as a necessity for improving quality. 
Our analyses nonetheless show that clinical leads played a key role in any improvement effort. Making leaders commit to improving patient care was seen as a sine qua non for the inspections to succeed. While this supports an argument for seeing external assessments as a platform from which clinicians can negotiate with senior management, ${ }^{36}$ we would add that inspections might empower leaders and managers as well as clinicians. ${ }^{37}$ Some important ways in which leaders wield power within organisations are by calling on shared organisational values and by leveraging facts and reasoning. ${ }^{38}$ Clinical leaders can facilitate change processes and organisational learning by providing front-line clinicians with an arena for sharing information and a context for reflecting on shared information. ${ }^{39}$ The effectiveness of such leadership approaches can be bolstered by the inspections. The sepsis inspections highlighted patient safety, which is a laudable and legitimate shared value goal in the emergency departments, and they did so by providing tangible facts for the leaders to leverage vis-a-vis their subordinates and team members.

Recent research has found that educative approaches to regulation can succeed when regulators are able to leverage existing norms and accountability structures in the regulated community. ${ }^{40}$ This seems to be the case for the sepsis inspection. They have resulted in an improved understanding of the inherent complexities in the care of patients with sepsis, and the improved understanding brings forth organisational commitment and readiness for change, which are pivotal for improvement to take place. These processes also parallel findings from a study of professionals' motivation in hospital accreditation, which showed that external assessment opened up opportunities for collaborative learning and promoted understanding of the whole organisation across organisational boundaries. ${ }^{41}$ Similarly, the importance of the system perspective runs like a red thread through our interviews, both in terms of the inspection teams' competencies and in terms of how clinicians and managers address quality challenges in their own organisations.

It should be noted that this argument presupposes the existence of norms and accountability structures in the inspected organisation that can be harnessed for quality improvement. If the management and staff are not amenable to the inspection team's suggestions, the learning process will likely flounder. Whether the organisation responds to the inspection with organisational commitment is not only dependent on which organisation is being inspected but also on the theme of the inspection. The way the clinical, patient-centred focus provided a legitimisation for the sepsis inspections is a case in point.

Other contextual factors are also important. If the healthcare organisation already performs at a high level, the inspection might not be able to contribute significantly to further improvement. ${ }^{29}$ Furthermore, healthcare organisations often require financial resources to initiate improvement efforts, and in some cases they also need external improvement support. ${ }^{329}$ Consequently, our findings cannot be extrapolated as universally applicable for all types of inspections within all types of organisations.

\section{Policy implications}

Even if performance data is key, focusing exclusively on performance data and quantifiable targets might pose a risk by underestimating the measurement problems or risks of health organisations gaming the system. ${ }^{42}$ There is a risk that externally imposed standards in external assessment schemes may end up being perceived as a 'tick-box' exercise for the clinicians involved. ${ }^{43}$

When assessing performance within a specific area of patient care, the inspection authorities should use indicators that carry a clinical relevance for those working in the inspected organisations. To achieve this, they need to operationalise clinical standards into indicators that are well-suited for identifying subpar services and sensitive for improvement. It is also necessary to combine the evaluation of the indicators with a thorough understanding of the clinical processes at work. The task of the inspectors is to review the numbers and bring to the table an assessment of why the hospital might fail to meet the standards. This might necessitate prioritising regulatory resources so that external clinical experts are extensively involved both in the preparation stages, when relevant indicators are identified, and during the on-site inspections.

Organisations do of course review their own performance data and make efforts to improve without the help of external inspections. When it is feasible to make improvements through smaller adjustments, it is likely that the hospitals will do so. Addressing the underlying challenges inherent in tasks like sepsis diagnosis and treatment, on the contrary, entails both deeper analysis and more profound systemic changes. Here, the clinical data and assessments provided by the inspection team can be of great value for the management and staff in their search for flexible solutions for quality improvement. Here, however, we also see the limits of this approach to inspections: For the inspection to succeed, the organisation must have sufficient personnel and resources that can be mobilised for a sustained commitment to quality improvement.

Acknowledgements We thank the focus group participants for devoting their time to this study. We also thank the patient organisations for their involvement in the research project, the inspection teams for participating in data collection and the staff at the Norwegian Board of Health Supervision for developing the sepsis inspection. Professor Geir Sverre Braut translated the inspection report, for which we are most grateful.

Contributors GH contributed to conception and design, planning and conducting interviews, initial analysis, interpretation of findings, authoring original draft, making critical revisions and approving the final version of the manuscript. ILT contributed to conception and design, interpretation of findings, making critical revisions and approving the final version of the manuscript. JCF contributed to conception and design, interpretation of findings, making critical revisions and approving the final version of the manuscript. GTB contributed to conception and design, interpretation of findings, making critical revisions and approving the final version of the manuscript. EH contributed to conception and design, planning and conducting 
interviews, initial analysis, interpretation of findings, making critical revisions and approving the final version of the manuscript.

Funding The authors have not declared a specific grant for this research from any funding agency in the public, commercial or not-for-profit sectors.

Competing interests None declared.

Patient consent for publication Not required.

Ethics approval The research project was reviewed and approved by the Regional Ethics Committee of Norway North (Identifier: 2015/2195) and the Norwegian Data Protection Authority (Identifier: 15/01559).

Provenance and peer review Not commissioned; externally peer reviewed.

Data availability statement No data are available. This is a qualitative study and therefore the data generated is not suitable for sharing beyond that contained within the report. Further information can be obtained from the corresponding author.

Supplemental material This content has been supplied by the author(s). It has not been vetted by BMJ Publishing Group Limited (BMJ) and may not have been peer-reviewed. Any opinions or recommendations discussed are solely those of the author(s) and are not endorsed by BMJ. BMJ disclaims all liability and responsibility arising from any reliance placed on the content. Where the content includes any translated material, BMJ does not warrant the accuracy and reliability of the translations (including but not limited to local regulations, clinical guidelines, terminology, drug names and drug dosages), and is not responsible for any error and/or omissions arising from translation and adaptation or otherwise.

Open access This is an open access article distributed in accordance with the Creative Commons Attribution Non Commercial (CC BY-NC 4.0) license, which permits others to distribute, remix, adapt, build upon this work non-commercially, and license their derivative works on different terms, provided the original work is properly cited, appropriate credit is given, any changes made indicated, and the use is non-commercial. See: http://creativecommons.org/licenses/by-nc/4.0/.

\section{ORCID iDs}

Gunnar Husabø http://orcid.org/0000-0002-8726-1769

Einar Hovlid http://orcid.org/0000-0003-0300-4405

\section{REFERENCES}

1 Shaw CD, Groene O, Berger E. External institutional strategies: accreditation, certification, supervision. In: Busse R, Klazinga N, Panteli D, eds. Improving healthcare quality in Europe, 2019: 203-31.

2 Sutherland K, Leatherman S. Regulation and quality improvement - A review of the evidence. London: The Health Foundation, 2006.

3 Smithson R, Richardson E, Roberts J, et al. Impact of the care quality Commission on provider performance: room for improvement? 2018.

4 Schaefer C, Wiig S. Strategy and practise of external inspection in healthcare services - a Norwegian comparative case study. Safety in Health 2017;3:1-9.

5 Weiner BJ, Amick H, Lee S-YD. Conceptualization and measurement of organizational readiness for change: a review of the literature in health services research and other fields. Med Care Res Rev 2008;65:379-436.

6 Nonaka I. A dynamic theory of organizational knowledge creation. Organization Science 1994;5:14-37.

7 Oude Wesselink SF, Lingsma HF, Reulings PGJ, et al. Does government supervision improve stop-smoking counseling in midwifery practices? Nicotine Tob Res 2015;17:572-9.

8 Oude Wesselink SF, Lingsma HF, Ketelaars CAJ, et al. Effects of government supervision on quality of integrated diabetes care: a cluster randomized controlled trial. Med Care 2015;53:784-91.

9 Castro-Avila A, Bloor K, Thompson C. The effect of external inspections on safety in acute hospitals in the National health service in England: a controlled interrupted time-series analysis. J Health Serv Res Policy 2019;24:182-90.

10 Allen T, Walshe K, Proudlove N, et al. Measurement and improvement of emergency department performance through inspection and rating: an observational study of emergency departments in acute hospitals in England. Emerg Med J 2019;36:326-32.

11 Flodgren G, Gonçalves-Bradley DC, Pomey M-P. External inspection of compliance with standards for improved healthcare outcomes. Cochrane Database Syst Rev 2016;12:Cd008992.

12 Hovlid E, Braut GS, Hannisdal E, et al. Mediators of change in healthcare organisations subject to external assessment: a systematic review with narrative synthesis. BMJ Open 2020;10:e038850.

13 Hovlid E, Frich JC, Walshe K, et al. Effects of external inspection on sepsis detection and treatment: a study protocol for a quasiexperimental study with a stepped-wedge design. BMJ Open 2017; 7:e016213.

14 Morgan DL. The focus group Guidebook. Thousand Oaks, CA: SAGE Publications, 1997

15 Sayer A. Realism and social science. Thousand Oaks: Sage, 2000.

16 O'Brien BC, Harris IB, Beckman TJ, et al. Standards for reporting qualitative research: a synthesis of recommendations. Acad Med 2014:89:1245-51.

17 Norwegian Board of Health Supervision. Introduction to the supervisory authorities and the supervision of child welfare services, social services and health and care services in Norway, 2019. Available: https://www.helsetilsynet.no/en/introduction-tothe-supervisory-authorities-and-the-supervision-of-child-welfareservices-social-services-and-health-and-care-services-in-norway

18 Goodwin A, Srivastava V, Shotton $\mathrm{H}$, et al. Just say sepsis. A review of the process of care received by patients with sepsis. London: National Confidential Enquiry into Patient Outcome and Death, 2015

19 Rhodes A, Evans LE, Alhazzani W, et al. Surviving sepsis campaign: international guidelines for management of sepsis and septic shock: 2016. Intensive Care Med 2017;43:304-77.

20 Plata-Menchaca EP, Ferrer R, Ruiz Rodríguez JC, et al. Antibiotic treatment in patients with sepsis: a narrative review. Hosp Pract 2020;319:1-11.

21 Gatewood Medley O'Keefe, Wemple M, Greco S, et al. A quality improvement project to improve early sepsis care in the emergency department. BMJ Qual Saf 2015;24:787-95.

22 Husabø G, Nilsen RM, Flaatten H, et al. Early diagnosis of sepsis in emergency departments, time to treatment, and association with mortality: an observational study. PLoS One 2020;15:e0227652.

23 ISO. ISO/IEC TS 17022:2012. Conformity Assessment Requirements and Recommendations for Content of a Third-Party Audit Report on Management Systems. Geneva: International Organization for Standardization, 2012.

24 National Institute for Health and Care Excellence. Sepsis. quality standard QS161, 2017.

25 Dellinger RP, Levy MM, Rhodes A, et al. Surviving sepsis campaign: international guidelines for management of severe sepsis and septic shock, 2012. Intensive Care Med 2013;39:165-228.

26 Husabø G, Nilsen RM, Solligård E, et al. Effects of external inspections on sepsis detection and treatment: a stepped-wedge study with cluster-level randomisation. BMJ Open 2020;10:e037715.

27 Braun V, Clarke V. Using thematic analysis in psychology. Qual Res Psychol 2006;3:77-101.

28 Pawson R, Greenhalgh T, Harvey G, et al. Realist review--a new method of systematic review designed for complex policy interventions. J Health Serv Res Policy 2005;10 Suppl 1:21-34.

29 Castro AC. Evaluating the effect of external inspections of the care quality. Commission of acute NHS hospitals in England. University of York, 2018.

30 Hood C, Scott C, James O, et al. Regulation inside government: waste watchers, quality police, and sleaze-busters. Oxford: Oxford University Press, 1999.

31 Walshe K, Phipps D. Developing a strategic framework to guide the Care Quality Commission's programme of evaluation. London: CQC, 2013.

32 Åsprang AF, Frich JC, Braut GS. Organizational impact of governmental audit of blood transfusion services in Norway: a qualitative study. Transfus Apher Sci 2015;53:228-32.

33 El-Jardali F, Jamal D, Dimassi H, et al. The impact of hospital accreditation on quality of care: perception of Lebanese nurses. Int $J$ Qual Health Care 2008;20:363-71.

34 Levy MM, Rhodes A, Phillips GS, et al. Surviving sepsis campaign: association between performance metrics and outcomes in a 7.5year study. Crit Care Med 2015;43:3-12.

35 Paccioni A, Sicotte C, Champagne F. Accreditation: a cultural control strategy. Int J Health Care Qual Assur 2008;21:146-58.

36 Baskind R, Kordowicz M, Chaplin R. How does an accreditation programme drive improvement on acute inpatient mental health wards? an exploration of members' views. J Ment Health 2010;19:405-11.

37 Walshe K. Regulating healthcare: a prescription for improvement? Berkshire: McGrawHill Education, 2003.

38 Van Wart M, Suino PArmonk NY, ed. Leadership in public organizations : an introduction. 2nd ed. London: M.E. Sharpe, 2012.

39 Hovlid E, Bukve O, Haug K, et al. Sustainability of healthcare improvement: what can we learn from learning theory? BMC Health Serv Res 2012;12:235. 
40 Erp J, Wallenburg I, Bal R. Performance regulation in a networked healthcare system: from cosmetic to institutionalized compliance. Public Adm 2020;98:46-61.

41 Greenfield D, Pawsey M, Braithwaite J. What motivates professionals to engage in the accreditation of healthcare organizations? Int J Qual Health Care 2011;23:8-14.
42 Bevan G, Hood C. What's measured is what matters: targets and gaming in the english public health care system. Public Adm 2006;84:517-38.

43 Campbell SM, Chauhan U, Lester $\mathrm{H}$. Primary medical care provider accreditation (PMCPA): pilot evaluation. Br J Gen Pract 2010;60:e295-304 